\title{
Familial calcification of the basal ganglia with cerebrospinal fluid pleocytosis
}

\author{
L MEHTA, J Q TROUNCE, J R MOORE, AND I D YOUNG \\ From the Department of Child Health, Leicester Royal Infirmary, Leicester.
}

SUMMARY Two related infants with microcephaly, spastic quadriplegia, and profound retardation are reported. Both showed extensive bilateral symmetrical calcification of the basal ganglia with cerebrospinal fluid pleocytosis.

The differential diagnosis of intracranial calcification in a microcephalic retarded infant includes both environmental and genetic causes so that the provision of a recurrence risk in an isolated case may pose a difficult problem. A cerebrospinal fluid pleocytosis might well suggest an infectious aetiology.

The purpose of this paper is to report two related infants who presented in this way and to draw attention to an inherited disorder recently delineated by Aicardi and Goutières, ${ }^{1}$ in which calcification of the basal ganglia is associated with microcephaly, persistent cerebrospinal fluid lymphocytosis, and progressive cerebral atrophy. The cases described here provide further support for autosomal recessive inheritance in this condition.

\section{Case reports}

CASE 1

This case (III.13, fig 1) was the first child of healthy consanguineous Muslim parents. He was born at 38 weeks by normal delivery after an uneventful drug free pregnancy. Apgar scores were 8 at one minute

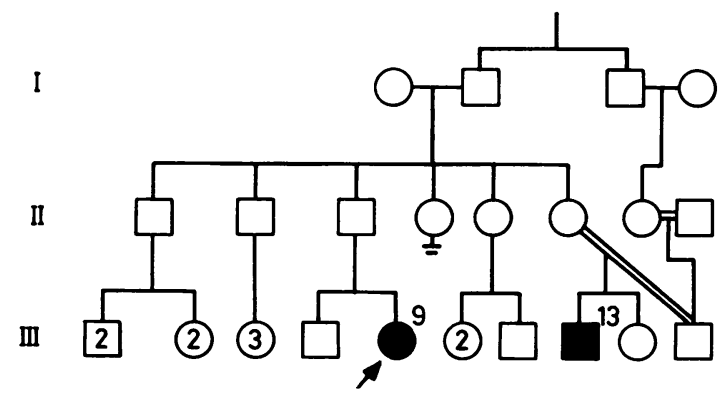

FIG 1 Family pedigree.

Received for publication 21 January 1985.

Accepted for publication 17 February 1985 and 9 at five minutes. Birth weight was $1.87 \mathrm{~kg}$ and head circumference $29.6 \mathrm{~cm}$.

Convulsive activity was noted on the second day and continued throughout life, showing a poor response to anticonvulsants. By the age of 2 months he was noted to be hypertonic with nystagmus and poor head growth. At 8 months abnormal findings included severe developmental delay, microcephaly $(\mathrm{OFC}=38.5 \mathrm{~cm})$, spastic quadriplegia, nystagmus with normal fundi, and little if any visual awareness. The infant died in an almost vegetative state at the age of 9 months in severe congestive cardiac failure, previous investigations having shown a large patent ductus arteriosus. Permission for necropsy was not granted.

Normal investigations included a congenital infection screen, urea and electrolytes, liver function tests, blood calcium, phosphate, magnesium, and alkaline phosphatase, and amino acids. Serial cerebrospinal fluid analyses revealed a persistent lymphocytic pleocytosis as indicated in the table. No organisms were detected and culture was invariably negative for both bacteria and viruses.

A skull $x$-ray at 4 weeks showed no intracranial calcification. However, a CT scan at 6 months showed bilateral calcification in the thalami and basal ganglia along with dilatation of the ventricular system and Sylvian fissures consistent with cortical atrophy (fig 2).

\section{CASE 2}

This 1 year old female infant (III.9, fig 1) was the second child of healthy unrelated Muslim parents. She was born at 37 weeks by Caesarean section because of breech presentation. The pregnancy was uneventful and drug free. Growth parameters at birth were weight $2.4 \mathrm{~kg}$ and head circumference $30.5 \mathrm{~cm}$.

No major problems were noted until the age of 9 
TABLE Cerebrospinal fluid changes in cases 1 and 2.

\begin{tabular}{|c|c|c|c|c|c|c|}
\hline & \multirow[t]{2}{*}{ Protein $(g / l)$} & \multirow[t]{2}{*}{ Glucose (mmolii) } & \multirow[t]{2}{*}{ Red cells $\left(\times 10^{\circ} / l\right)$} & \multicolumn{3}{|c|}{ White cells } \\
\hline & & & & $\left(\times 10^{6} / l\right)$ & $\%$ polymorphs & $\%$ lymphocytes \\
\hline \multicolumn{7}{|l|}{ Case 1} \\
\hline Age 2 days & 1.5 & $2 \cdot 9$ & 2150 & 5 & & \\
\hline 2 weeks & $1 \cdot 7$ & $2 \cdot 5$ & 10 & 89 & 20 & 80 \\
\hline 4 weeks & 1.5 & $2 \cdot 6$ & 0 & 25 & 10 & 90 \\
\hline 7 weeks & 1.6 & $3 \cdot 0$ & 0 & 55 & 35 & 65 \\
\hline 9 weeks & $0 \cdot 3$ & 1.9 & 5 & 34 & 6 & 94 \\
\hline
\end{tabular}

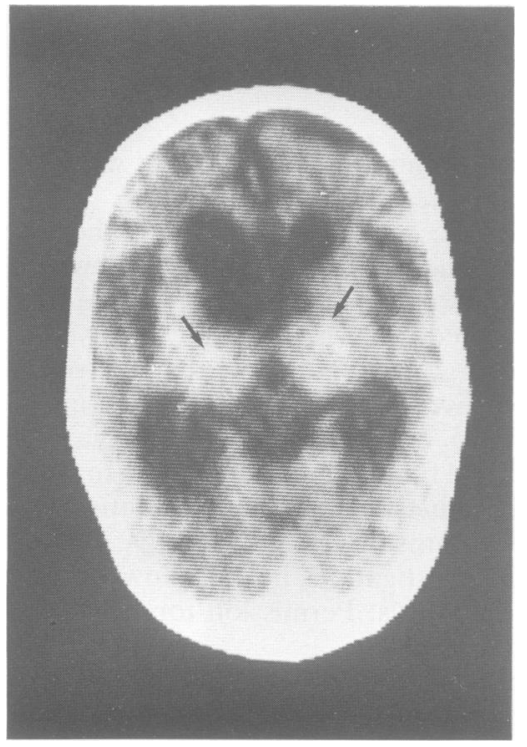

FIG 2 CT scan of case 1 showing bilateral intrathalamic calcification (arrowed), ventricular dilatation, and widening of the Sylvian fissures.

weeks when she was found to be jittery and failing to thrive with generalised hypertonia. Subsequent developmental progress has been grossly impaired to the extent that she has never smiled or been observed to maintain eye to eye contact. The jitteriness has persisted although no actual convulsions have been witnessed.

Examination at the age of 8 months revealed microcephaly $(\mathrm{OFC}=39 \mathrm{~cm})$, fine horizontal nystagmus with normal fundi, spastic quadriplegia, and persisting primitive reflexes. No abnormal pigmentation, hepatosplenomegaly, or dysmorphic features were noted. On recent assessment at 11 months the child was severely globally retarded and unresponsive to external stimuli with very limited visual attention.

Investigations giving normal results included a congenital infection screen, liver function tests, blood ammonia, amino acids, chromosomes, and ERG. A VER at the age of 8 months showed a very simple wave form with delay in the major positive peak. No vacuolated lymphocytes were seen in peripheral blood. Serum calcium was marginally raised on two occasions between 2 and 4 months with corrected values of 2.63 and $2.66 \mathrm{mmol} / \mathrm{l}$ (NR $2 \cdot 1$ to $2 \cdot 6$ ). On other occasions normal results were obtained. Alkaline phosphatase and parathormone assays were normal.

At 9 weeks cerebrospinal fluid showed a lymphocytosis (table) with no organisms on either direct examination or culture. Skull $x$-ray at 9 weeks showed bilateral calcification in the basal ganglia which was confirmed by ultrasonography (fig 3 ). A CT scan at 3 months showed changes identical to those observed in case 1 (fig 4).

\section{FAMILY HISTORY}

The family pedigree (fig 1 ) shows that cases 1 and 2 are related and that the parents of case 1 are consanguineous. The extended family pedigree reveals several other instances of consanguinity

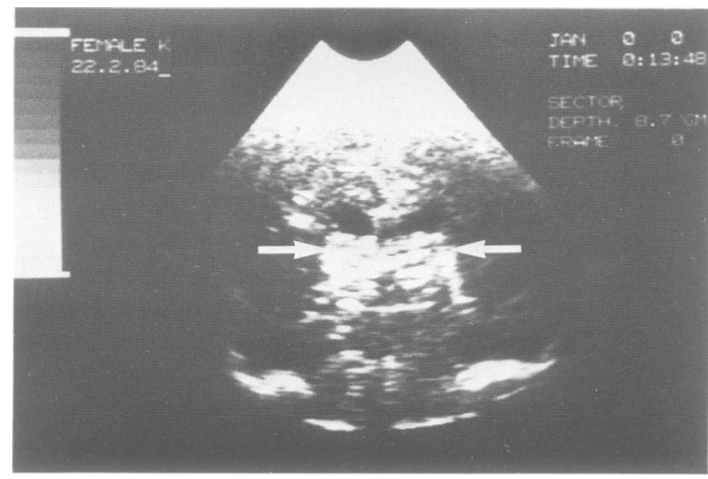

FIG 3 Coronal ultrasound scan of case 2 showing increased echodensity in both thalami (arrowed) resulting from localised calcification. The lateral ventricles are dilated. 


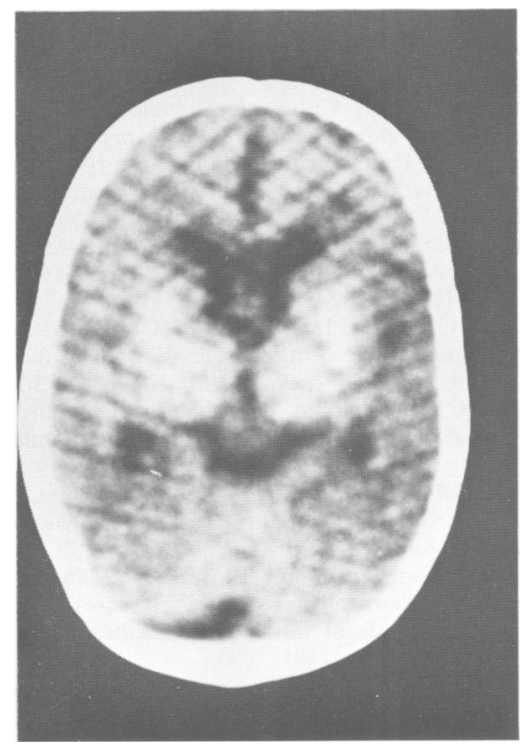

FIG 4 CT scan of case 2 confirming the presence of extensive bilateral basal ganglia calcification.

although the parents of case 2 are believed to be unrelated.

The sibs and parents of these cases have been examined and found to be normal. All have normal blood calcium and phosphate levels with no evidence of intracranial calcification on skull $x$-ray other than pineal calcification in the parents of case 1 .

\section{Discussion}

The two infants we have described have an identical condition characterised by increasing microcephaly, progressive spastic quadriplegia, failure to achieve any developmental milestones, jitteriness or frank convulsions, cerebrospinal fluid pleocytosis, and calcification of the basal ganglia with brain atrophy. No infective or consistent biochemical abnormality has been detected. The fact that these children are related and that one child has consanguineous parents indicates that they are likely to have an autosomal recessive disorder.

There is evidence for the existence of several different forms of familial calcification of the basal ganglia which can be summarised as follows. Even within these subgroups heterogeneity is apparent.

(1) Autosomal dominant, late onset. ${ }^{2-7}$ This entity presents during or after the fourth decade. Clinical abnormalities may include pyramidal, extrapyramidal, and cerebellar disturbance as well as convulsions and impaired intellectual function. Progression is slow.

(2) Autosomal recessive, late onset. ${ }^{8-10}$ The clinical features are very similar to those of the autosomal dominant form, with particular involvement of the extrapyramidal and cerebellar systems. This condition may be a variant of pseudohypoparathyroidism without dysmorphism. ${ }^{8} 9$

(3) Autosomal recessive, early onset and slowly progressive. "1 (family 1) This form presents in the second or third year and leads to severe mental retardation, emaciation, and spastic quadriplegia by the age of 20 years.

(4) Autosomal recessive, non-progressive. ${ }^{12}$ In this condition calcification of the basal ganglia is associated with non-progressive mental retardation, steatorrhoea, and episodic pseudoobstruction which may prove fatal.

(5) Autosomal recessive, early onset and rapidly progressive. ${ }^{111}$ (family 2) 1.344 This form presents in the first few weeks or months of life with convulsions and microcephaly leading to spastic quadriplegia, cortical blindness, profound mental retardation with emaciation, and death within a few years. Other findings may include nystagmus, ${ }^{11} 14$ optic atrophy, ${ }^{11} 14$ retinal changes, ${ }^{11} 13$ and glaucoma. ${ }^{14}$

Intracranial calcification may also occur in several inherited dysmorphic syndromes including the cerebro-oculo-facial syndrome (COFS), Cockayne's syndrome, and pseudohypoparathyroidism. The term 'Fahr's disease' is sometimes used in the context of non-arteriosclerotic calcification of the cerebral vessels, also known as idiopathic familial cerebrovascular ferrocalcinosis. ${ }^{15}$ Fahr's original report $^{16}$ was of idiopathic calcification of the cerebral vessels in a 50 year old man, and since this was an isolated case it seems inappropriate to use the eponymous 'Fahr's disease' when discussing any or all of the aforementioned genetic disorders.

The disorder in the cases we have described appears identical to that documented by Aicardi and Goutières ${ }^{\prime}$ in eight children from five families. Their illness was characterised by persistent cerebrospinal fluid pleocytosis, primarily a lymphocytosis, and raised cerebrospinal fluid protein. Similar cerebrospinal fluid changes were noted in the sibs reported by Babbitt et al. ${ }^{13}$ If the patients in these two reports are included with our own, this gives a total of 13 affected children (eight boys and five girls) from seven families with definite parental consanguinity in four instances. Consequently autosomal recessive inheritance is very probable. We suspect that the congenital heart disease in our case 1 is coincidental since this has not been described in other cases. 
Attention has been drawn to the difficulty of assessing the recurrence risk when dealing with an isolated case of microcephaly and intracranial calcification. ${ }^{17}$ The presence of a pleocytosis in the cerebrospinal fluid might well suggest a non-genetic inflammatory aetiology, so that this severe autosomal recessive form of calcification of the basal ganglia is likely to provide a serious trap for the unwary genetic counsellor.

The authors are grateful to Drs L A Comley and M I Levene for providing details of cases 1 and 2 respectively, to Dr N Messios for reviewing the CT scans, and to Mrs Susan Kenney for typing the manuscript.

\section{References}

' Aicardi J, Goutières F. A progressive familial encephalopathy in infancy with calcifications of the basal ganglia and chronic cerebrospinal fluid lymphocytosis. Ann Neurol 1984;15:49-54.

2 Foley J. Calcification of the corpus striatum and dentate nuclei occurring in a family. J Neurol Neurosurg Psychiatry 1951; 14:253-61.

${ }^{3}$ Roberts PD. Familial calcification of the cerebral basal ganglia and its relation to hypoparathyroidism. Brain 1959; LXXXII: 599-609.

${ }^{4}$ Pilleri G. A case of morbus Fahr (non-arteriosclerotic idiopathic intracerebral calcification of the blood vessels) in three generations. Psychiatr Neurol (Basel) 1966;152:43-58.

5 Adachi M, Wellman KF, Volk BW. Histochemical studies on the pathogenesis of idiopathic non-arteriosclerotic cerebral calcification. J Neuropathol Exp Neurol 1968;27:483-99.
${ }^{6}$ Moskowitz MA, Winickoff RN, Heinz ER. Familial calcification of the basal ganglions. A metabolic and genetic study. $N$ Engl J Med 1971;285:72-7.

${ }^{7}$ Boller F, Boller M, Gilbert J. Familial idiopathic cerebral calcification. J Neurol Neurosurg Psychiatry 1977;40:280-5.

${ }^{8}$ Matthews WB. Familial calcification of the basal ganglia with response to parathormone. J Neurol Neurosurg Psychiatry 1957;20:172-7.

9 Nyland H, Skre H. Cerebral calcinosis with late onset encephalopathy. An unusual type of pseudohypoparathyroidism. Clin Genet 1978;13:132A.

${ }^{10}$ Smits MG, Gabreëls FJM, Thijssen HOM, et al. Progressive idiopathic strio-pallido-dentate calcinosis (Fahr's disease) with autosomal recessive inheritance. Eur Neurol 1983;22:58-64.

"1 Melchior JC, Benda CE, Yakovlev PI. Familial idiopathic cerebral calcifications in childhood. Am J Dis Child 1960;99: 787-802.

12 Cockel R, Hill EE, Rushton DI, Smith B, Hawkins CF. Familial steatorrhoea with calcification of the basal ganglia and mental retardation. $Q J$ Med 1973;XLII:771-83.

13 Babbitt DP, Tang T, Dobbs J, Berk R. Idiopathic familial cerebrovascular ferrocalcinosis (Fahr's disease) and review of differential diagnosis of intracranial calcification in children. AJR 1969;105:352-8.

${ }^{14}$ Kousseff BG. Fahr disease. Report of a family and a review. Acta Paediatr Belg 1980;33:57-61.

${ }^{15}$ Millen SJ, Pulec JL, Kane PM. Fahr's disease-an otolaryngologic perspective. Arch Otolaryngol 1982;108:591-4.

${ }^{16}$ Fahr T. Idiopathische Verkalkung der Hirngefässe. Zentralbl Allg Pathol 1930;50:129-33.

17 Baraitser M, Brett EM, Piesowicz AT. Microcephaly and intracranial calcification in two brothers. J Med Genet 1983;20:210-2.

Correspondence and requests for reprints to Dr I D Young, Department of Child Health, PO Box 65, Clinical Sciences Building, Leicester Royal Infirmary, Leicester LE2 7LX. 